Aquaculture

September 2015, Volume 446, Pages 17-24

http://dx.doi.org/10.1016/j.aquaculture.2015.04.018

http://archimer.ifremer.fr/doc/00260/37147/

(c) 2015 Elsevier B.V. All rights reserved.

\title{
A microarray-based analysis of oocyte quality in the European clam Ruditapes decussatus
}

\author{
Teixeira De Sousa Joana ${ }^{1,2}$, Milan Massimo ${ }^{3}$, Pauletto Marianna ${ }^{3}$, Bargelloni Luca ${ }^{3}$, \\ Joaquim Sandra $^{2,4}$, Matias Domitília ${ }^{2,4}$, Matias Ana Margarete ${ }^{2}$, Quillien Virgile ${ }^{1}$, Leitão Alexandra ${ }^{2,5}$, \\ Huvet Arnaud ${ }^{1, *}$
}

\footnotetext{
${ }^{1}$ IFREMER, UMR CNRS 6539, Laboratoire des Sciences de l'Environnement Marin, BP 70, 29280

Plouzané, France

2 IPMA, Avenida 5 de Outubro, 8700-305, Olhão, Portugal

${ }^{3}$ Department of Comparative Biomedicine and Food Science, University of Padova, Viale dell'Università

16, Agripolis 35020 Legnaro, Italy

${ }^{4}$ CIIMAR, Interdisciplinary Centre of Marine and Environmental Research, University of Porto, Rua dos

Bragas 289, 4050-123 Porto, Portugal

${ }^{5}$ Environmental Studies Center, Qatar University, Doha, Qatar

* Corresponding author: Arnaud Huvet, Tel.: + 332982246 93; fax: + 33298224653 ;

email address : Arnaud.Huvet@ifremer.fr
}

\begin{abstract}
:
A microarray-based analysis was performed with the objective of describing genomic features of oocytes and looking for potential markers of oocyte quality in the economically important European clam, Ruditapes decussatus. Oocytes of 25 females from Ria de Aveiro, Western coast of Portugal $\left(40^{\circ} 42^{\prime} \mathrm{N} ; 08^{\circ} 40 \mathrm{~W}\right)$ were selected for this study and oocyte quality was estimated by success of D-larval rate under controlled conditions, which appeared to vary from 0 to $95 \%$. By genome-wide expression profiling with a DNA microarray, 526 probes appeared differentially expressed between two groups representing the largest and smallest value of $D$ larval rates, named good (represented by a mean $D$ larval yield of $57 \pm 22 \%)$ and poor $(9 \pm 5 \%)$ quality oocytes. Enrichment analysis showed "Lysosome" (dre04142) as the single pathway represented in the enriched KEGG pathway terms, with 8 genes coding for putative Cathepsins. Furthermore, differentially expressed genes involved in oocyte protection (DnaJ (Hsp40), Hsp70, Cyclophilin B, PDI), maturation (Cam-PDE1C, PRDM9, G protein), sperm-egg interaction (PDI, G protein) and apoptosis (TNF) were also identified. From these, the apoptosis pathway was supposed to assume an important role in oocyte quality as the mRNA level of Caspase 8 appeared also negatively correlated with the D-larval yield. Finally, a G-protein transcript was identified as more abundant in poor quality oocytes, which underlines the importance of release prophase I block and meiotic maturation in the oocytes of this species. This study provided new highly valuable information on genes specifically expressed by mature oocytes of $R$. decussatus, for further understanding of the mechanisms of early development in this species.
\end{abstract}




\section{Highlights}

- Description of genomic features of Ruditapes decussatus oocytes; - Identification of potential markers of oocyte quality in the European clam $R$. decussatus; Provide information on genes expressed by oocytes, allowing a better understanding of early development in $R$. decussatus.

\section{Statement of relevance}

Understand the mechanisms of early development in the European clam $R$. decussatus.

Keywords : Ruditapes decussatus, oocyte, developmental success, gene expression, marine bivalve, transcriptomics 


\section{Introduction}

Today, the European clam, Ruditapes decussatus, is considered one of the most economically important bivalve species in Portugal and in other Southern European countries where it is extensively produced and harvested. The European clam constitutes the majority of revenue from aquaculture in Portugal, representing $76 \%$ of the national annual shellfish production (DGPA 2012). The production of this species is dependent upon the collection of wild seed, which has been compromised in recent years due to recruitment failure and severe mortalities (Matias et al. 2009). To address this issue, artificial spawning and larval rearing programs were developed to provide an alternative source of seed (Matias et al. 2009); Moreover, diseases caused by a wide range of microorganisms are associated with large economic losses in $R$. decussatus which is a high vulnerable species to physical stress and pathogens (Moreira et al., 2012). For all these reasons improvements are still needed to achieve robust and reproducible seed production in captivity. Among the improvements of aquaculture of $R$. decussatus, the evaluation and the control of gamete quality are essential.

In hatcheries, bivalve gametes are usually obtained by applying thermal shocks to mature broodstock. However, an alternative method of gonad dissection (or stripping) exists, which is an easier and faster method of accessing gametes. This technique can only be used in species where oocytes can be fertilized directly after dissecting the gonad, such as the Pacific oyster Crassostrea gigas. Unfortunately, the oocytes of $R$. decussatus are not ready to be fertilized after the dissection, representing a further problem for the production of this species (Colas and Dubé 1998; Hamida et al. 2004; Pauletto et al., 2014).

High variability in reproductive success is commonly observed in most bivalve hatcheries and it has been shown to be partly attributable to gamete quality, sperm-egg interaction and differential viability of genotypes (Boudry et al. 2002). Therefore, gamete quality has received increasing attention and several studies have focused on egg or sperm quality in different species (Bobe and Labbé 2010; Boulais et al., 2015; Corporeau et al. 2012; Galbraith and Vaughn 2009; Lonergan et al. 2003; Rime et al. 2004; Suquet et al. 2010). Gamete quality is influenced by many environmental and biological factors. In marine species such as bivalves and fishes, the main factors that appear to affect bivalves gamete quality are nutrition (availability of food, algal consumption and nutritional quality of microalgae, namely the proportion of the essential fatty acids), abiotic environmental factors (temperature, photoperiod and salinity), husbandry practices (spawning induction, egg postovulatory ageing and gamete handling post-stripping), stress and pollutants including biotic pressure with harmful microorganisms (e.g.; Angel-Dapa et al. 2010; Bobe and Labbé 2010; Cannuel and Beninger 2005; Delgado and Pérez Camacho 2005; Galbraith and Vaughn 2009; Migaud et al. 2013) and parental health condition (Boudry et al. 2002; Luttikhuizen et al., 2011). 
Oocyte quality, defined as the egg's potential to produce viable offspring, can be characterized by embryo development yields (Kjorsvik et al. 1990) and is determined in marine bivalves basing on D-larval yields, that is considered the best descriptor of oocyte quality in this class (e.g.; Boulais et al., 2015; Corporeau et al. 2012; Massapina et al. 1999; Suquet et al. 2014). In terms of oocyte quality proxies (i.e., parameters that can be measured in oocytes to predict the development rate of embryos) in bivalves, several criteria have been tested, such as gonad color (Mason 1958) and mean oocyte diameter as a direct consequence of nutrition (Cannuel and Beninger 2005). Egg size and shape have also been tested, with large eggs surviving better than small eggs (Baynes and Howell 1996; Kraeuter et al. 1981). Finally, oocyte organic matter and lipid content have been described as important predictors of oocyte quality since a significant relationship was observed between these biochemical parameters, broodstock condition index, and hatching rate (Cannuel and Beninger 2005; Massapina et al. 1999). However, not all indicators consistently correlate with 'quality' in all bivalve species, with the most reliable indicators being fertilization success, Dlarval yields and survival; three criteria of interest in aquaculture (Migaud et al. 2013). Recent studies focusing on oocyte quality proxies in fish have suggested an important role of oocyte vitelline reserves (lipid, protein, mRNA and vitamin content) that are required for embryo and larval development (Yue et al., 2013; Aegerter et al, 2005; Dong et al., 2004).

In the present study, we conducted a genome-wide expression profiling of clam oocytes sampled from 25 females displaying variability in subsequent D-larval yields obtained from experimental conditioning and fertilization. We employed a custom oligonucleotide DNA microarray containing 51,678 probes representing unique contigs described and validated in de Sousa et al. (2014). The main objectives of the present work were to analyze molecular features of $R$. decussatus oocytes and to look for candidate transcripts to be further tested as markers of clam oocyte quality.

\section{Material and Methods}

\subsection{Oocyte sampling}

Broodstock of $R$. decussatus (> $35 \mathrm{~mm}$ shell length) were collected from Ria de Aveiro $\left(40^{\circ} 42^{\prime} \mathrm{N}\right.$; $\left.08^{\circ} 40 \mathrm{~W}\right)$ (western coast of Portugal) and conditioned to accelerate their gonad development in the experimental bivalve hatchery of the Portuguese Institute of Sea and Atmosphere (IPMA) in Tavira, Portugal. Fifty-five individuals were placed in experimental 30-L tanks in a flow through system at $20 \pm 1{ }^{\circ} \mathrm{C}$ with a daily phytoplankton supply equivalent to $4 \%$ of the dry weight of the clams' soft tissue (Utting and Millican 1997). Food regime consisted of algal mixtures containing a volume of $1 / 3$ Isochrysis aff galbana, 1/3 Chaetoceros calcitrans and 1/3 Skeletonema costatum (Ria Formosa autochthone clone). The water was enriched with this mixed diet and distributed to the tanks at a flow rate of 0.6 to $0.8 \mathrm{~L} \mathrm{~min}^{-1}$. Microalgae 
were cultured in $80 \mathrm{~L}$ bags with seawater (salinity $\left.=36 \pm 1 \mathrm{~g} \mathrm{~L}^{-1}\right)$ filtered $(0.45 \mu \mathrm{m})$, UV treated, and enriched with sterilised $\mathrm{f} / 2$ medium (Guillard 1975), in a temperature-controlled room at 20 $\pm 2 \stackrel{\circ}{ } \mathrm{C}$ under continuous illumination (9900 lux). For diatom culture, sodium metasilicate (molar concentration in final medium - $1.06 \times 10^{-4} \mathrm{M}$ ) was added as a silica source in seawater microalgae culture at a concentration of $1 \mathrm{~mL} \mathrm{~L}^{-1}$. A continuous aeration was provided to enhance growth and prevent the algae from settling.

After 2 to 4 weeks, clams were induced to spawn on four different sampling dates by standard thermal stimulation, with temperature alternating between 5 to $28 \pm 1^{\circ} \mathrm{C}$, during $30 \mathrm{~min}$ and $1 \mathrm{~h}$, respectively (Joaquim et al., 2008). To avoid uncontrolled fertilization, females once identified were stored in individual containers for spawning.

From each female, the number of oocytes released were estimated (mean of triplicate counts of $100 \mu \mathrm{L}$ from a $200 \mathrm{~mL}$ volume) and around 20000 oocytes were taken, rinsed with iso-osmotic ammonium formate $(3 \% \mathrm{w} / \mathrm{v})$ to remove salt, and homogenized in Extract-all (Eurobio) and stored in liquid nitrogen for further RNA extraction. The remaining oocytes of each female spawning were fertilized by addition of a mixture of sperm from 6 to 7 males (different mixture for each sampling time), to provide a ratio of around ten spermatozoa per oocyte estimated in a microscope view (Joaquim et al. 2008). A total of 11250 eggs were then, incubated in triplicate $500 \mathrm{ml}$ tanks (37 500 per tank), with 1- $\mathrm{mm}$ filtered and UV-irradiated seawater, maintained at 20 $\pm 2 \stackrel{\circ}{ } \mathrm{C}$, at a density of 75 eggs per $\mathrm{ml}$. After $48 \mathrm{~h}$ of incubation, the D-larvae were collected on a $30-\mu \mathrm{m}$ mesh screen and concentered in $50 \mathrm{~mL}$. Live D-shaped larvae number (translucent or non-D-shaped larvae were not counted) was estimated by microscopic count $(3 \times 1 \mathrm{~mL})$. The veliger rate (\% of D-larvae) was calculated as the ratio between the number of D-larvae at $48 \mathrm{~h}$ post fertilization and the number of incubated eggs.

\subsection{RNA extraction}

Total RNA was purified by following the manufacturer instructions (Extract-all, Eurobio). RNA quality and integrity were analyzed on the Agilent bioanalyzer using RNA nanochips and Agilent RNA 6000 nanoreagents (Agilent Technologies, Waldbronn, Germany). RNA concentrations were measured at $260 \mathrm{~nm}$ using a ND-1000 spectrophotometer (Nanodrop Technologies) using the conversion factor $1 \mathrm{OD}=40 \mathrm{mg} / \mathrm{mL}$ total RNA. Samples were stored at $-80^{\circ} \mathrm{C}$ until further use.

\subsection{Ruditapes decussatus DNA microarray}

Gene expression analyses of all the oocytes from the 25 females analyzed were performed using an array composed of 59,951 out of 60,000 probes, representing 51,709 different $R$. decussatus contigs, as described by de Sousa et al. (2014). The percentage of annotated transcripts represented on the microarray was $85.7 \%$. Probe sequences and other 
details on the microarray platform can be found in the GEO database (http://www.ncbi.nlm.nih.gov/geo/) under accession number GPL17766.

\subsection{Labeling and microarray hybridization}

Sample labeling and hybridization were performed according to the Agilent One-Color Microarray-Based Gene Expression Analysis protocol with the Low Input Quick Amp Labeling kit. Briefly, for each sample $100 \mathrm{ng}$ of total RNA was linearly amplified and labeled with Cy3dCTP. A mixture of 10 different viral poly-adenylated RNAs (Agilent Spike-In Mix) was added to each RNA sample before amplification and labeling to monitor microarray analysis workflow. Labeled cRNA was purified with Qiagen RNAeasy Mini Kit, and sample concentration

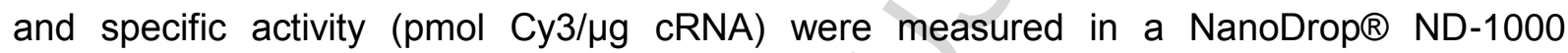
spectrophotometer. A total of $600 \mathrm{ng}$ of labeled CRNA was prepared for fragmentation by adding $5 \mu \mathrm{l} 10 \mathrm{X}$ Blocking Agent and $1 \mu \mathrm{l}$ of $25 \mathrm{X}$ Fragmentation Buffer, heated at $60^{\circ} \mathrm{C}$ for 30 min, and finally diluted by addition with $25 \mu \mathrm{l} 2 \mathrm{X}$ GE Hybridization buffer. A volume of $40 \mu \mathrm{l}$ of hybridization solution was then dispensed in the gasket slide and added to the microarray slide (each slide containing eight arrays). Slides were incubated for $17 \mathrm{~h}$ at $65^{\circ} \mathrm{C}$ in an Agilent hybridization oven, subsequently removed from the hybridization chamber, quickly submerged in GE Wash Buffer 1 to disassemble the slides and then washed in GE Wash Buffer 1 for approximately 1 minute followed by one additional wash in pre-warmed $\left(37^{\circ} \mathrm{C}\right)$ GE Wash Buffer 2.

\subsection{Data acquisition, correction and normalization}

Hybridized slides were scanned at $2 \mu \mathrm{m}$ resolution using an Agilent G2565BA DNA microarray scanner. Default settings were modified to scan the same slide twice at two different sensitivity levels (XDR $\mathrm{Hi}$ 100\% and XDR Lo 10\%). The two linked images generated were analyzed together, data were extracted and background subtracted using the standard procedures contained in the Agilent Feature Extraction (FE) Software version 10.7.3.1. The software returns a series of spot quality measures in order to evaluate the quality and the reliability of spot intensity estimates. All control features (positive, negative, etc.), except for Spike-in (Spike-in Viral RNAs), were excluded from subsequent analyses.

Raw gene expression data of all the oocytes from the 25 females analyzed were deposited in the GEO database under accession number GSE54954. Spike-in control intensities were used to identify the best normalization procedure for each dataset. After normalization, spike intensities are expected to be uniform across the experiments of a given dataset. Normalization procedures were performed using R statistical software. Quantile normalization always outperformed cyclic loess and quantile-normalized data were further adjusted for the known between-experiments batch effects by implementing the parametric 
Combat in $\mathrm{R}$, to avoid bias due to different batches of the oligonucleotide microarray (Johnson et al. 2007). Normalized data were deposited in GEO archive under accession number GSE54954.

\subsection{Data analysis}

A Principal Component Analysis (PCA), using the TMeV 4.5.1 (TIGR MULTIEXPERIMENT VIEWER) (Saeed et al., 2003) was applied to all 51,709 transcripts, to assess the distribution of the 25 oocyte samples.

One-way ANOVA parametric tests were used to investigate the significance of the factor time on the D-larval yield after angular transformation (STATGRAPHICS Centurion $\mathrm{XV} . \mathrm{II}$ ) and on the gene expression, after a base 10 logarithmic transformation (TMeV 4.5.1 TIGR MULTIEXPERIMENT VIEWER), using a p-value cut-off of 0.05. Statistical analyses were performed using Student's t-test in order to define good and poor quality oocytes of $R$. decussatus. T-Tests ( $p$-value $<0.01$ ) were computed to compare gene expression between good and poor quality oocytes of $R$. decussatus (TMeV 4.5.1). The resulting gene lists were then filtered, and only those probes with fold change $(F C)>1.5$ were considered differentially transcribed.

Hierarchical clustering was performed using TMeV 4.5.1 on statistically significant transcripts to group experimental samples basing on similarity of the overall experimental expression profiling.

A quantitative correlation analysis was performed by SAM (Significance Analysis of Microarray) $(F D R=5 \%)$ to identify genes with a correlation between mRNA levels and D-larval yield.

A more systematic and functional interpretation for significant gene lists was obtained using an enrichment analysis with the Database for Annotation, Visualisation, and Integrated Discovery (DAVID) software (Huang et al., 2009). "KEGG Pathway", "Biological process" (BP), "Molecular function" (MF) and "Cellular component" (CC) analyses were carried out by setting the gene count equal to 2 and the ease equal to 0.1 . Because the DAVID database contains functional annotation data for a limited number of species, it was necessary to link $R$. decussatus transcripts with sequence identifiers that could be recognized in DAVID. This process was accomplished using dedicated Blast searches performed with Blastx against zebrafish Ensembl proteins. Finally, Danio rerio Ensembl Gene IDs were obtained from the corresponding Ensembl protein entries using the BIOMART data mining tool (http://www.ensembl.org/biomart/martview/). D. rerio IDs corresponding to differentially transcribed clam genes as well as all of the transcripts that were presented on the array were then used to define a "gene list" and a "background" in DAVID, respectively. 


\section{Results and Discussion}

\subsection{D-larval yield}

Oocytes of 25 females were analyzed in this study. High variability between individuals was observed for D-larval development, ranging from 0 to $95 \%$.

Although fertilization of oocytes was carried out with a different mixture of sperm in each of the four sampling dates, we still observed oocyte quality variation within each date (0 to $41 \%$ in first spawn/sampling time; 4 to $46 \%$ in second spawn/sampling time; 22 to $95 \%$ in third spawn/sampling time and 5 to $88 \%$ in the fourth spawn /sampling time). Additionally, a oneway ANOVA ( $p>0.05)$ revealed that there was no statistically significant difference among the D-larval yields across the four sampling times showing that there was no noticeable effect of sperm pools on D-larval yield. Considering these statistical results and since the environmental conditions and experimental procedures, like the spawning inducer technique (thermal stimulation), were kept uniform across oocyte batches, we assume that this variation was most likely to be due to the intrinsic quality of oocytes of each female. Individual variability is commonly observed in molluscs (Corporeau et al. 2012; Massapina et al. 1999) as well as in fishes (Salze et al. 2005) and may originate from biochemical and molecular composition of oocytes and broodstock nutrition. From the 25 studied females, two groups were designed representing the largest and smallest value of a block of distributed $D$ larval rate, between which there is a significant difference for early developmental success of fertilized oocytes $(p<0.001)$ : a good quality group of 8 samples with a $D$-larval yield superior to $40 \%$ (mean \pm SD $=57 \pm 22 \%$ ) and a poor quality group of 10 samples with a D-larval yield inferior to $20 \%(9 \pm 5 \%)$. The remaining 7 females presented an intermediary D-larval yield $(27 \pm 6 \%)$ and were not chosen for gene expression analysis (Fig 1). Sampling times, containing oocytes fertilized by a different mixture of sperm, were randomly distributed in these two groups, confirming the absence of sperm pools effect on the D-larval yield.

\subsection{Identification of Differentially Expressed Genes between good and poor quality oocytes}

In order to compare gene expression between good and poor quality oocytes, we carried out student's $T$ tests $(p<0.01)$ on the 10 samples with the lowest $D$-larval yield versus the 8 samples with the highest D-larval yield mentioned before. This analysis identified a list of 526 significant probes ( $F C>1.5$ ), corresponding to 359 unique transcripts $(A)$ visually presented in hierarchical clustering using Pearson's correlation (Fig 2). A total of 361 differentially expressed probes were more abundant in good quality oocytes with a FC ranging from 1.5 to 11.6 , while a total of 165 differentially expressed probes were more abundant in poor quality oocytes with a FC ranging from 1.5 to 10.2. 
A putative annotation with zebrafish Ensembl Gene IDs was obtained for 323 differentially expressed probes. These annotated transcripts were used to define a gene list for functional annotation with DAVID. Enrichment analysis showed 1 KEGG, 7 BP term, 1 CC term, and 7 MF terms to be significantly over-represented (B). "Lysosome" (dre04142), was the only pathway represented in the enriched KEGG pathway terms, with 8 genes. Cathepsin $F$ and cathepsin $Z$ were found among the differentially expressed genes. Cathepsins activity was already proven to be related to the oocyte quality of several species (e.g.; Balboula et al., 2010; Warzych et al., 2012; Zhang et al., 2008). Cathepsin Z belongs to the group of cysteine proteases, which represents the major component of lysosomal proteolysis system (Kao and Huang, 2008). Previous studies suggest this gene may be involved in yolk metabolism, particularly during oocyte maturation of carps. Cathepsin Z was also localized in other organelles of eggs, thus pointing out additional functions of CatZ in fish eggs (Kao and Huang, 2008). The Cathepsin F showed a pivotal role during protease activation and/or yolk proteolysis, specifically during vitellogenesis in fish eggs (Raldúa et al., 2005). The accumulation of its mRNA in killifish ovarian follicles that occurs during oocyte maturation was supposedly related to the requirement of cathepsin $\mathrm{F}$ maternal transcripts during early embryogenesis rather than for the specific processing of yolk proteins during oocyte maturation (Raldúa et al., 2005). In the genus Ruditapes, cathepsins were mainly suggested to be involved in molecular responses to diseases (Allam et al., 2014; Moreira et al., 2012).

\subsection{Chaperone proteins are main determinants of good quality oocytes in Ruditapes decussatus}

Among the genes that had higher abundance in good quality oocytes, we noticed the presence of chaperone molecules, DnaJ (Hsp40) homolog subfamily C member 27-A, Heat Shock 70 kDa protein 12A (Hsp70), Cyclophilin B and Protein Disulfide Isomerase family A (PDI), that we consider to be either the result of the thermal shock employed for spawning and/or potential markers of oocyte quality, this latest being emphasized by a literature review also in species where thermal shock is not employed or not tested in the published studies (e.g. C.gigas). Chaperones are proteins that assist the non-covalent folding or unfolding of other proteins and are widespread in cells across taxonomic groups. Protein folding is a key step for normal protein synthesis, but is also severely affected by stressors such as high/ low temperature or oxidative stress. Several chaperones over-expressed under cellular stress conditions counteract the potential damage caused by protein misfolding (Macario 2007). In the present study, chaperones found to be more abundant in good quality oocytes might be related, at least partially, with the method used to induce clam spawning (i.e. thermal shock, with temperature alternately increasing from 5 to $28 \pm 1^{\circ} \mathrm{C}$ ). It is possible that chaperone proteins play a major role in protecting oocytes from thermal shock or other cellular stresses 
induced by manipulation. Good quality eggs might be those that are able to mount a more efficient response to the challenge inherent in thermal induction of spawning. Our results are based on evidence at the mRNA level and will require confirmation at the protein level. However, with the exception of DnaJ (Hsp40), it is very remarkable to observe that the same chaperones described in the present study were recently found to be associated, at the protein level, with high quality oocytes collected by stripping in the Pacific oyster C. gigas, with some of them being maternal mRNAs essential for fertilization, first cleavage and embryonic genome activation (Corporeau et al., 2012). In any case, considering that the method employed for spawning in clam hatchery is thermal shock, chaperone proteins should be further tested as putative biomarkers of oocyte quality for further practical application. Comparison with naturally spawned oocytes would also be of further interest considering that temperature change is one of the factors that trigger clam spawning in the environment (Pérez-Camacho et al., 2003)

DnaJ (Hsp40) homolog was the most abundant chaperone at the mRNA level in good quality oocytes $(F C=5.3)$. DnaJ contains the $J$ domain through which the chaperone binds to Hsp70s to determine their activity by stabilizing their interaction with substrate proteins (Fan et al. 2003; Qiu et al. 2006). In turn, Hsp70 (FC=1.7) binds to nascent polypeptides to facilitate correct folding and prevents the aggregation of non-native and misfolded proteins (Corporeau et al. 2000; Delelis-Fanien et al. 1997). Hsp70 is a well-known stress related protein already described in several bivalve species, including $C$. gigas (Corporeau et al. 2012; Tanguy et al. 2004), the Mediterranean mussel Mytilus galloprovinciallis (Cellura et al. 2007), the manila clam R. philipinarum (Kang et al. 2006; Moreira et al. 2012) and the European clam R. decussatus (Gestal et al. 2007; Moreira et al. 2012). Indeed, in C. gigas, it was suggested that greater abundance of the protein HSP70 could be related to better protein folding in two-cell stage embryos and better protection of oocytes and early embryos directly exposed to oxidative stress, temperature and $\mathrm{pH}$ fluctuations in the sea water (Corporeau et al. 2012). It was also reported that the chaperone function of Hsp70 is required for protection against stress-induced apoptosis (Mosser et al. 2000). Thus, we can again pave the hypothesis that this higher expression of DnaJ (Hsp40) homolog and Hsp70 in good quality oocytes might be implicated in the protection and maintenance of developing oocytes in $R$. decussatus. Finally, the extensive set of Hsp70 genes (88 putative homologs) in the $C$. gigas genome, which corresponds to the increase of "stress genes" recently reported in the oyster genome (Zhang et al. 2012) suggests a complexity of the chaperone responses in marine bivalves that merits further investigation in clams, too.

Cyclophilin $\mathrm{B}(\mathrm{FC}=1.5)$ was also more highly expressed in good quality oocytes. Cyclophilins are known to catalyze protein folding in cooperation with heat-shock proteins (Corporeau et al. 2012). Such proteins are collectively known as immunophilins and it was 
suggested that cyclophilins have a diverse array of additional cellular functions, including roles as chaperones and in cell signaling (Wang and Heitman 2005). The functions reported for cyclophilins in model organisms imply that these proteins could have a crucial role in oocyte viability and immune protection, thus explaining their higher mRNA expression in gametes that have higher D-larval yields.

A last chaperone molecule, found more abundant in good quality oocytes, is Protein Disulfide Isomerase family $A(P D I)(F C=1.5)$. This is a peptidylprolyl isomerase that belongs to the immunophilin family, being also advantageous for the viability and immune protection of eggs and early embryos of Pacific oyster (Corporeau et al. 2012). A few studies have suggested that PDIs are involved in oocyte development (Ohashi et al. 2013), probably by mediating the formation of disulfide bonds in proteins, particularly Vitellogenin (Liao et al. 2008). Furthermore, several studies proposed an essential role of PDI for the sperm-egg fusion at fertilization (Calvert et al. 2003; Ellerman et al. 2006), leading us to think that sperm-egg interaction could also be one of the reasons to explain the high individual variability in oocytes quality when estimated by $D$ larval yields. Moreover, in a microarraybased analysis of gametogenesis in two Portuguese populations of $R$. decussatus, this gene was also found down regulated in individuals from Ria Formosa lagoon, where spawning induction is less successful (de Sousa et al. 2014), supporting the hypothesis that spermegg interaction can participate to the differences between populations of this species as well.

\subsection{Prophase I block and meiotic maturation in Ruditapes decussatus oocytes}

With the exception of some cases like oysters, where oocytes can achieve completion of meiosis in seawater after stripping (Osanai 1985), oocytes of most marine bivalve species like $R$. decussatus are arrested at prophase of the first meiosis and spend their entire growth phase in a state analogous to the G2/M transition of a mitotic cell cycle (Colas and Dubé 1998). To release this block, hormonal stimulation or other stimuli are needed for the oocytes to pass through metaphase, which is why oocytes cannot be fertilized directly after dissecting the gonad (Colas and Dubé 1998; Hamida et al. 2004). In addition, in some bivalve species, a second barrier to development occurs at metaphase I, prior to extrusion of the first polar body, until fertilization releases this metaphase arrest and allows further stages of maturation to take place (Colas and Dubé 1998). The molecular cascade, and the underlying genes involved in this phenomenon, has been little studied in bivalves showing mainly the crucial role of $\mathrm{Ca}^{2+}$ signaling pathway during oocyte maturation (e.g.; Abdelmajid et al. 1993; Colas and Dubé 1998; Deguchi and Morisawa 2003; Leclerc et al. 2000; Stricker and Smythe 2001; Zhang et al. 2009). It has been suggested that continuously synthesized, short-lived proteins are responsible for maintaining metaphase arrest in some molluscan oocytes, with cyclin regulatory proteins as good candidates since their disappearance triggered 
metaphase/anaphase transition and polar body extrusion (Colas and Dubé 1998). In Ruditapes and other molluscs, calcium may act via a calcium calmodulin-kinase since calcium calmodulin antagonists were able to prevent metaphase I release and cyclin degradation upon fertilization (Abdelmajid et al. 1993; Colas and Dubé 1998; Leclerc et al. 2000; Whitaker 1996; Zhang et al. 2009). In this work we found the enzyme Calcium/calmodulin-dependent 3',5'-cyclic nucleotide phosphodiesterase 1C (Cam-PDE1C) ( $F C=1.7)$ among the genes more abundant in good quality oocytes. In a recent study made by Pauletto et al. (2014), gene expression profiles suggested calcium regulation (e.g.; regucalcin, calmodulin) importance in the control of oocyte competence. Despite little is known about the molecular regulation of intracellular $\mathrm{Ca}^{2+}$ occurring during oocytes maturation in bivalves, these preliminary results pointed out a few important genes possibly involved in such a complex mechanism that have to be further explored functionally (Gui and Zhu, 2012).

Among the genes more abundant in poor quality oocytes, we observed Guanine nucleotide-binding protein subunit beta-like protein 1 ( $G$ protein) and Histone-lysine $\mathrm{N}$ methyltransferase PRDM9; genes known to be involved in oocyte maturation and in the transition of oocytes through meiosis (Voronina and Wessel 2004; Williams et al. 1996; Wu et al. 2013). There are also several studies that indicate that $G$ proteins are involved in oocyte growth and maturation (Voronina and Wessel 2004; Williams et al. 1996). G-proteins may also be involved in releasing the oocytes from an arrest inherent within the oocyte. For example, in starfish, progression of an oocyte into meiotic divisions is dependent upon activation of subunits of G-proteins (Chiba and Hoshi 1995; Jaffe et al. 1993; Thomas et al. 2002). Although $G$ proteins are involved in several different processes, based on these examples, it is possible that the overexpression of this protein deregulates the oocyte maturation of $R$. decussatus. More precisely, the initiation of meiosis and the transition of the oocytes through metaphase I may be impacted. Moreover, it was reported that these proteins could also be involved in the important process of sperm-egg interaction (Fard Jahromi and Shamsir 2013; Leclerc and Kopf 1999; Lee et al. 2005) similar to the chaperone molecule PDI mentioned before.

Finally, Histone-lysine N-methyltransferase PRDM9 appeared as a relevant candidate to oocyte quality in $R$. decussatus as it displayed the highest differential ( $F C=10.2)$ between the two groups of clam oocytes. This gene is thought to be essential for proper meiotic progression in species in which it was documented. Actually, it has been proposed that PRDM9 binds to specific sites in the genome of oocytes and spermatocytes, where its methyltransferase activity leads to a local enrichment of histone $\mathrm{H} 3$ peptide dimethylated on lysine 4 (H3K4me2) and recruits the meiotic recombination machinery (Wu et al. 2013). During meiosis, homologous recombination occurs preferentially at defined hotspots. In 
mammals, the fast-evolving DNA-binding domain of PRDM9 has been identified as a major hotspot determinant that may explain the rapid rates of hotspot redistribution during evolution (Hochwagen and Marais 2010). Although the PRDM genes are not well studied in invertebrates, their importance in the cell cycle already described in vertebrates (Baudat et al. 2010) led us to suggest that PRDM9 could play an important role in the meiotic progression of $R$. decussatus oocytes and therefore in their maturation. Further gene expression studies of these candidates are needed to compare spawned and stripped oocytes at different location into the gonad to dig into the processes of gamete maturation along the genital ducts.

\subsection{Stress and Apoptosis}

Apoptosis is an intrinsic, genetically controlled process, responsible for destroying redundant, dysfunctional or damaged cells (Motta et al. 2013). Among the genes that were more abundant in poor quality oocytes, some appeared to be implicated in cell responses to stress. Genes belonging to apoptosis pathway and p53 signaling pathway appeared over expressed in poor quality oocytes. It is known that the p53 superfamily proteins originally evolved to mediate programmed cell death of damaged germ cells or to protect germ cells from genotoxic stress (Vilgelm et al. 2010; Walker et al. 2011). Thus, we can hypothesize that the greater abundance of genes in the p53 signaling pathway in poor quality oocytes could be due to a stress suffered by the cells, thus affecting fertilization success.

In the list of more abundant genes in poor quality oocytes we also observed the presence of Tumor necrosis factor receptor (TNF) $(F C=2.4)$. TNF is one of the factors that activate the death receptor-dependent pathway by binding to cell surface death receptors. The activation of this pathway results in the activation of Caspase-8 (Trounson et al. 2013), negatively correlated with D-larval yield in the present work. The presence of this factor, together with the presence of the genes belonging to apoptosis pathway, corroborates the hypothesis of the high incidence of programmed cell death in oocytes with lowest D-larval yield. Interestingly, the same superfamily of cell membrane receptors was found down-regulated in one Portuguese population of $R$. decussatus where spawning induction responses appeared lower (de Sousa et al. 2014). This superfamily includes FAS, CD40, CD27, and RANK, receptors for Tumor Necrosis Factor a (TNFa), an inflammatory cytokine produced by macrophages/monocytes during acute inflammation and responsible for a diverse range of signaling events within cells, leading to necrosis or apoptosis (Idriss and Naismith 2000).

Considering the entire dataset composed of 25 females, quantitative correlations between microarray data and D larval yields were evaluated via a SAM quantitative correlation analysis (FDR $=5 \%$ ). The results showed a total of 6 probes significantly correlated with the D-larval yield $(C)$. Of these 6 probes, 5 were negatively correlated with the D-larval 
yield and only 2 probes were annotated by similarity and associated with known proteins: Caspase-8 and Transcription factor E2F5 (Fig 3). The role of Caspase-8, which correlated negatively with D-larval yield, is very interesting since caspases represent a family of intracellular cysteine proteases linked both to the initial and final stages of apoptosis in numerous types of cells (Johnson and Bridgham 2002). Particularly, there are several studies that show the importance of caspases in the death by apoptosis of unfertilized ovulated oocytes (Johnson and Bridgham 2002; Papandile et al. 2004; Reynaud and Driancourt 2000; Trounson et al. 2013). Additionally, the negative correlation of E2F5 with the D-larval yield suggests the deregulation of the cell cycle and the normal development of gametes by this protein.

In bivalves and specifically in $R$. decussatus, the gonad passes through several developmental stages from sexual rest to ripe and spent (Delgado and Pérez Camacho 2005; Matias et al. 2013). In these last stages mature oocytes are spawned while those that are not released begin their resorption in the gonad. In this study all the oocytes were spawned by induction and were expected to be mature and ready to be fertilized. However, based on our results, it could be possible that over-expression of apoptosis-related genes is triggered as a consequence of unsolved cell stress, like thermal stress, affecting negatively the fertilization success.

\section{Conclusion}

Individual variability in oocyte quality is commonly observed in marine molluscs and is one of the most relevant problems in establishing a successful hatchery-based production of several marine species (e.g.; Bobe and Labbé 2010; Boudry et al. 2002; Corporeau et al. 2012; Massapina et al. 1999). Using a microarray-based analysis, we identified several genes that were differentially present according to oocyte quality, estimated here on potential to produce D-larvae. Genes coding for the chaperone proteins are suggested to be involved in important roles for the oocyte protection. Apoptosis appeared as one important pathway that we found more abundantly represented in poor quality oocytes and negatively correlated with the D-larval yield, noticeable by the presence of caspase-8, linked to programmed cell death in numerous types of cells. Among the candidate genes, DnaJ (Hsp40) homolog, tumor necrosis factor receptor and caspase 8 appeared to be candidates of particular interest for more specific and precise individual functional investigation in relationship with reproductive success of $R$. decussatus in hatcheries, one of the major bottlenecks hampering the development of commercial aquaculture of the European clam.

In the context of growing environmental pressure, harmful micro-organisms (e.g. toxic algae and pathogens), may affect the maturation and fecundity of marine organisms either by decreasing the amount and quality of gametes or by affecting embryonic development 
(Vasconcelos et al., 2010). Therefore, further studies on oocyte quality in the European clam and in marine bivalves in general, as $C$. gigas, severely affected by massive mortality (EFSA, 2010), would be of big interest to understand if recurrent biotic pressures may impact significantly gamete quality and more globally recruitment.

\section{Acknowledgments}

This study was supported by the European program REPROSEED EU Grant No. 245119 (http://www.reproseed.eu/). The authors are grateful to the REPROSEED partners J.L. Nicolas, R. Robert and P. Boudry for their support during the course as well as P. Sourdaine, P. Favrel and C. Lelong for helpful discussion. The authors are grateful to Emma TimminsSchiffman for her help in editing the English language.

\section{References}

Abdelmajid H, Guerrier P, Colas P, et al. (1993) Role of calcium during release of mollusc oocytes from their blocks in meiotic prophase and metaphase. Biol Cell 78:137-143.

Aegerter, S., Jalabert, B. and Bobe, J. (2005) Large scale real-time PCR analysis of mRNA abundance in rainbow trout eggs in relationship with egg quality and post-ovulatory ageing. Mol. Reprod. Dev., 72: 377-385

Allam B, Pales Espinosa E, Tanguy A, Jeffroy F, Le Bris C, Paillard C. (2014) Transcriptional changes in Manila clam (Ruditapes philippinarum) in response to Brown Ring Disease. Fish Shellfish Immunol. 41, 2-11.

Angel-Dapa, M.A., Rodríguez-Jaramillo, C., Cáceres-Martínez, C.J., Saucedo, P.E. (2010) Changes in Lipid Content of Oocytes of the Penshell Atrina maura as a Criterion of Gamete Development and Quality: A Study of Histochemistry and Digital Image Analysis. J. Shellfish Res. 29, 407-413.

Balboula, AZ, Yamanaka, K, Sakatani, M, Hegab, AO, Zaabel, SM, Takahashi, M (2010) Cathepsin B activity is related to the quality of bovine cumulus oocyte complexes and its inhibition can improve their developmental competence. Mol. Reprod. Dev., 77: 439-448.

Baudat F, Buard J, Grey C, et al. (2010) PRDM9 Is a Major Determinant of Meiotic Recombination Hotspots in Humans and Mice. Science 327:836-840. 
Baynes SM, Howell BR (1996) The influence of egg size and incubation temperature on the condition of Solea solea (L.) larvae at hatching and first feeding. J Exp Mar Biol Ecol 199:59-77.

Bobe J, Labbé C (2010) Egg and sperm quality in fish. Gen Comp Endocrinol 165:535-548.

Boudry P, Collet B, Cornette F, et al. (2002) High variance in reproductive success of the Pacific oyster (Crassostrea gigas, Thunberg) revealed by microsatellite-based parentage analysis of multifactorial crosses. Aquaculture 204:283-296.

Boulais M, Corporeau C, Huvet A, Bernard I, Quere C, Quillien V, Fabioux C, Suquet M (2015) Assessment of oocyte and trochophore quality in Pacific oyster, Crassostrea gigas, Aquaculture 437: 201-207.

Calvert ME, Digilio LC, Herr JC, Coonrod SA (2003) Oolemmal proteomics - identification of highly abundant heat shock proteins and molecular chaperones in the mature mouse egg and their localization on the plasma membrane. Reprod Biol Endocrinol 1:27.

Cannuel R, Beninger PG (2005) Is oyster broodstock feeding always necessary? A study using oocyte quality predictors and validators in Crassostrea gigas. Aquat Living Resour 18:35-43.

Cellura C, Toubiana M, Parrinello N, Roch P (2007) Specific expression of antimicrobial peptide and HSP70 genes in response to heat-shock and several bacterial challenges in mussels. Fish Shellfish Immunol 22:340-350.

Chiba, K., Hoshi, M. (1995) G-protein-mediated signal transduction for meiosis reinitiation in starfish oocyte. Prog. Cell Cycle Res. 1, 255-263.

Colas P, Dubé F (1998) Meiotic maturation in mollusc oocytes. Semin Cell Dev Biol 9:539_ 548.

Corporeau, C.D., Angelier, N., Penrad-Mobayed, M. (2000). HSP70 is involved in the control of chromosomal transcription in the amphibian oocyte. Exp. Cell Res. 260, 222-232.

Corporeau C, Vanderplancke G, Boulais M, et al. (2012) Proteomic identification of quality factors for oocytes in the Pacific oyster Crassostrea gigas. J Proteomics 75:55545563. 
Deguchi R, Morisawa M (2003) External Ca2+ is predominantly used for cytoplasmic and nuclear $\mathrm{Ca}^{2+}$ increases in fertilized oocytes of the marine bivalve Mactra chinensis. $\mathrm{J}$ Cell Sci 116:367-376.

Delelis-Fanien C, Penrad-Mobayed M, Angelier N (1997) Molecular cloning of a cDNA encoding the amphibian Pleurodeles waltl $70-\mathrm{kDa}$ heat-shock cognate protein. Biochem Biophys Res Commun 238:159-164.

Delgado M, Pérez Camacho A (2005) Histological study of the gonadal development of Ruditapes decussatus (L.) (Mollusca: Bivalvia) and its relationship with available food. Sci. Mar. 69 (1): 87-97:

DGPA (2011) Recursos da Pesca. Série estatística, 2009. Direcção Geral das Pescas e Aquicultura. (22 A-B) (181 pp., Lisboa, (In portuguese)).

Dong, C.-H., Yang, S.-T., Yang, Z.-A., Zhang, L., Gui, J.-F. (2004). A C-type lectin associated and translocated with cortical granules during oocyte maturation and egg fertilization in fish. Dev. Biol. 265, 341-354.

EFSA (2010) Scientific Opinion of the Panel on Animal Health and Welfare on a request from the European Commission on the increased mortality events in Pacific oysters Crassostrea gigas. 8:1894-953.

Ellerman DA, Myles DG, Primakoff P (2006) A role for sperm surface protein disulfide isomerase activity in gamete fusion: evidence for the participation of ERp57. Dev Cell 10:831-837.

Fan C-Y, Lee S, Cyr DM (2003) Mechanisms for regulation of Hsp70 function by Hsp40. Cell Stress Chaperones 8:309-316.

Fard Jahromi SS, Shamsir MS (2013) Construction and Analysis of the Cell Surface's Protein Network for Human Sperm-Egg Interaction. ISRN Bioinforma 2013:1-8.

Galbraith H, Vaughn C (2009) Temperature and food interact to influence gamete development in freshwater mussels. Hydrobiologia 636:35-47.

Gestal, C., Costa, M., Figueras, A., Novoa, B. (2007) Analysis of differentially expressed genes in response to bacterial stimulation in hemocytes of the carpet-shell clam Ruditapes decussatus: identification of new antimicrobial peptides. Gene 406, 134 143. 
Gui, J., Zhu, Z. (2012) Molecular basis and genetic improvement of economically important traits in aquaculture animals. Chin. Sci. Bull. 57, 1751-1760.

Guillard RRL (1975) Culture of Phytoplankton for Feeding Marine Invertebrates. In: Smith WL, Chanley MH (eds) Cult. Mar. Invertebr. Anim. Springer US, pp 29-60

Hamida L, Medhioub M-N, Cochard JC, Pennec ML (2004) Evaluation of the effects of serotonin (5-HT) on oocyte competence in Ruditapes decussatus (Bivalvia, Veneridae). Aquaculture 239:413-420.

Hochwagen A, Marais GAB (2010) Meiosis: A PRDM9 Guide to the Hotspots of Recombination. Curr Biol 20:R271-R274.

Huang DW, Sherman BT, Lempicki RA (2009) Bioinformatics enrichment tools: paths toward the comprehensive functional analysis of large gene lists. Nucleic Acids Res. 37(1):113.

Idriss HT, Naismith JH (2000) TNF alpha and the TNF receptor superfamily: structurefunction relationship(s). Microsc Res Tech 50:184-195.

Jaffe LA, Gallo CJ, Lee RH, et al. (1993) Oocyte maturation in starfish is mediated by the beta gamma-subunit complex of a G-protein. J Cell Biol 121:775-783.

Joaquim S, Matias D, Moreno O (2008) Cultivo de bivalves em maternidade. Sevilla: Instituto de Investigación Y Formación Agraria Y Pesquera 84 p.

Johnson AL, Bridgham JT (2002) Caspase-mediated apoptosis in the vertebrate ovary. Reproduction 124:19-27.

Johnson WE, Li C, Rabinovic A (2007) Adjusting batch effects in microarray expression data using empirical Bayes methods. Biostatistics 8:118-127.

Kang Y-S, Kim Y-M, Park K-I, et al. (2006) Analysis of EST and lectin expressions in hemocytes of Manila clams (Ruditapes philippinarum) (Bivalvia: Mollusca) infected with Perkinsus olseni. Dev Comp Immunol 30:1119-1131.

Kao CM, Huang FL (2008) Cloning and expression of carp cathepsin Z: possible involvement in yolk metabolism. Comp. Biochem. Physiol., 149: 541-551.

Kennedy AM (2002) Reproduction of striped bass Morone saxatilis a structural, biochemical, and functional characterization of atresia. 
Kjorsvik E, Mangor-Jensen A, Holmefjord I (1990) Egg quality in fishes. Adv Mar Biol 26:71113.

Kraeuter JN, Castagna M, van Dessel R (1981) Egg size and larval survival of Mercenaria mercenaria (L.) and Argopecten irradians (Lamarck). J Exp Mar Biol Ecol 56:3-8.

Leclerc C, Guerrier P, Moreau M (2000) Role of dihydropyridine-sensitive calcium channels in meiosis and fertilization in the bivalve molluscs Ruditapes philippinarum and Crassostrea gigas. Biol Cell Auspices Eur Cell Biol Organ 92:285-299.

Leclerc P, Kopf GS (1999) Evidence for the role of heterotrimeric guanine nucleotide-binding regulatory proteins in the regulation of the mouse sperm adenylyl cyclase by the egg's zona pellucida. J Androl 20:126-134.

Lee K, Pisarska MD, Ko J-J, et al. (2005) Transcriptional factor FOXL2 interacts with DP103 and induces apoptosis. Biochem Biophys Res Commun 336:876-881.

Lelong, A., Hégaret, H., Soudant, P., Bates, S.S. (2012) Pseudo-nitzschia (Bacillariophyceae) species, domoic acid and amnesic shellfish poisoning: revisiting previous paradigms. Phycologia 51, 168-216.

Liao M, Boldbaatar D, Gong $\mathrm{H}$, et al. (2008) Functional analysis of protein disulfide isomerases in blood feeding, viability and oocyte development in Haemaphysalis longicornis ticks. Insect Biochem Mol Biol 38:285-295.

Lonergan P, Rizos D, Gutierrez-Adan A, et al. (2003) Oocyte and embryo quality: Effect of origin, culture conditions and gene expression patterns. Reprod Domest Anim 38:259-267.

Luttikhuizen, P.C., Honkoop, P.J.C., Drent, J. (2011) Intraspecific egg size variation and sperm limitation in the broadcast spawning bivalve Macoma balthica. J. Exp. Mar. Biol. Ecol. 396, 156-161.

Macario AJ L (2007) Molecular chaperones: Multiple functions, pathologies, and potential applications. Front Biosci 12:2588.

Mason J (1958) The breeding of the scallop, Pecten maximus (L.), in Manx waters. J Mar Biol Assoc U K 37:653-671. 
Massapina C, Joaquim S, Matias D, Devauchelle N (1999) Oocyte and embryo quality in Crassostrea gigas (Portuguese strain) during a spawning period in Algarve, South Portugal. Aquat Living Resour 12:327-333.

Matias D, Joaquim S, Leitao A, Massapina C (2009) Effect of geographic origin, temperature and timing of broodstock collection on conditioning, spawning success and larval viability of Ruditapes decussatus (Linn, 1758). Aquac Int 17:257-271.

Matias D, Joaquim S, Matias AM, et al. (2013) The reproductive cycle of the European clam Ruditapes decussatus (L., 1758) in two Portuguese populations: Implications for management and aquaculture programs. Aquaculture 406-407:52-61.

Migaud H, Bell G, Cabrita E, et al. (2013) Gamete quality and broodstock management in temperate fish. Rev Aquac 5:S194-S223.

Moreira R, Balseiro P, Romero A, et al. (2012) Gene expression analysis of clams Ruditapes philippinarum and Ruditapes decussatus following bacterial infection yields molecular insights into pathogen resistance and immunity. Dev Comp Immunol 36:140-149.

Mosser DD, Caron AW, Bourget L, et al. (2000) The Chaperone Function of hsp70 is required for Protection against Stress-Induced Apoptosis. Mol Cell Biol 20:71467159.

Motta CM, Frezza V, Simoniello P (2013) Caspase 3 in molluscan tissues: Localization and possible function. J Exp Zool Part Ecol Genet Physiol 319:548-559.

Ohashi Y, Hoshino Y, Tanemura K, Sato E (2013) Distribution of protein disulfide isomerase during maturation of pig oocytes. Anim Sci J Nihon Chikusan Gakkaihō 84:15-22.

Osanai K (1985) In vitro induction of germinal vesicle breakdown in oyster oocytes. Bull Mar Biol Stn Asamushi Tohoku Univ 181-9

Papandile A, Tyas D, O'Malley DM, Warner CM. (2004) Analysis of caspase-3, caspase-8 and caspase- 9 enzymatic activities in mouse oocytes and zygotes. Zygote 12:57-64.

Pauletto M, Milan M, de Sousa JT, Huvet A, Joaquim S, et al. (2014) Insights into Molecular Features of Venerupis decussata Oocytes: A Microarray-Based Study. PLoS ONE 9(12): e113925 
Pérez-Camacho A, Delgado M, Fernández-Reiriz MJ, Labarta U, 2003. Energy balance, gonad development and biochemical composition in the clam Ruditapes decussatus. Marine Ecology Progress Series 258:133-145.

Qiu X-B, Shao Y-M, Miao S, Wang L (2006) The diversity of the DnaJ/Hsp40 family, the crucial partners for Hsp70 chaperones. Cell Mol Life Sci CMLS 63:2560-2570.

Raldúa, D., Fabra, M., Bozzo, M.G., Weber, E., Cerdà, J. (2006) Cathepsin B-mediated yolk protein degradation during killifish oocyte maturation is blocked by an $\mathrm{H}+-$ ATPase inhibitor: effects on the hydration mechanism. Am. J. Physiol. Regul. Integr. Comp. Physiol. 290, R456-466.

Reynaud, K., Driancourt, M.A. (2000) Oocyte attrition. Mol. Cell. Endocrinol. 163, 101-108.

Rime H, Guitton N, Pineau C, et al. (2004) Post-ovulatory ageing and egg quality: A proteomic analysis of rainbow trout coelomic fluid. Reprod Biol Endocrinol 2:26.

Saeed Al, Sharov V, White J, et al. (2003) TM4: a free, open-source system for microarray data management and analysis. BioTechniques 34:374-378.

Salze G, Tocher DR, Roy WJ, Robertson DA (2005) Egg quality determinants in cod (Gadus morhua L.): egg performance and lipids in eggs from farmed and wild broodstock. Aquac Res 36:1488-1499.

de Sousa JT, Milan M, Bargelloni L, et al. (2014) A Microarray-Based Analysis of Gametogenesis in Two Portuguese Populations of the European Clam Ruditapes decussatus. PLoS ONE 9:e92202.

Stricker, S.A., Smythe, T.L. (2001) 5-HT causes an increase in cAMP that stimulates, rather than inhibits, oocyte maturation in marine nemertean worms. Dev. Camb. Engl. 128, $1415-1427$.

Suquet M, Labbé C, Brizard R, et al. (2010) Changes in motility, ATP content, morphology and fertilisation capacity during the movement phase of tetraploid Pacific oyster (Crassostrea gigas) sperm. Theriogenology 74:111-117.

Suquet M, Labbé C, Puyo S, Mingant C, Quittet B, et al. (2014) Survival, Growth and Reproduction of Cryopreserved Larvae from a Marine Invertebrate, the Pacific Oyster (Crassostrea gigas). PLoS ONE 9(4): e93486. 
Sutton ML, Gilchrist RB, Thompson JG (2003) Effects of in-vivo and in-vitro environments on the metabolism of the cumulus-oocyte complex and its influence on oocyte developmental capacity. Hum Reprod Update 9:35-48.

Tanguy A, Guo X, Ford SE (2004) Discovery of genes expressed in response to Perkinsus marinus challenge in Eastern (Crassostrea virginica) and Pacific (Crassostrea gigas) oysters. Gene 338:121-131.

Thomas P, Zhu Y, Pace M (2002) Progestin membrane receptors involved in the meiotic maturation of teleost oocytes: a review with some new findings. Steroids 67:511-517.

Trounson A, Gosden R, Eichenlaub-Ritter U (2013) Biology and Pathology of the Oocyte: Role in Fertility, Medicine and Nuclear Reprograming. Cambridge University Press

Utting SD, Millican PF (1997) Techniques for the hatchery conditioning of bivalve broodstocks and the subsequent effect on egg quality and larval viability. Aquaculture 155:45-54.

Vasconcelos, V., Azevedo, J., Silva, M., Ramos, V. (2010) Effects of Marine Toxins on the Reproduction and Early Stages Development of Aquatic Organisms. Mar. Drugs 8, 59-79.

Vilgelm AE, Washington MK, Wei J, et al. (2010) Interactions of the p53 protein family in cellular stress response in gastrointestinal tumors. Mol Cancer Ther 9:693-705.

Voronina E, Wessel GM (2004) By subunits of heterotrimeric G-proteins contribute to $\mathrm{Ca}^{2+}$ release at fertilization in the sea urchin. J Cell Sci 117:5995-6005.

Walker CW, Van Beneden RJ, Muttray AF, et al. (2011) p53 Superfamily proteins in marine bivalve cancer and stress biology. Adv Mar Biol 59:1-36.

Wang P, Heitman J (2005) The cyclophilins. Genome Biol 6:226.

Warzych, E, Wolc, A, Cieslak, A, and Lechniak-Cieslak, D (2012) 217 transcript abundance of cathepsin genes in cumulus cells as a marker of cattle oocyte quality. Reprod. Fertil. Dev. 25, 257-257.

Whitaker M (1996) Control of meiotic arrest. Rev Reprod 1:127-135. 
Williams CJ, Schultz RM, Kopf GS (1996) G protein gene expression during mouse oocyte growth and maturation, and preimplantation embryo development. Mol Reprod Dev 44:315-323.

Wu H, Mathioudakis N, Diagouraga B, et al. (2013) Molecular Basis for the Regulation of the H3K4 Methyltransferase Activity of PRDM9. Cell Rep 5:13-20.

Yue, H.-M., Li, Z., Wu, N., Liu, Z., Wang, Y., Gui, J.-F. (2013). Oocyte-Specific H2A Variant H2af1o Is Required for Cell Synchrony before Mid-Blastula Transition in Early Zebrafish Embryos. Biol. Reprod. biolreprod.113.108043.

Zhang G, Fang X, Guo X, et al. (2012) The oyster genome reveals stress adaptation and complexity of shell formation. Nature 490:49-54.

Zhang T, Rawson DM, Tosti L, Carnevali O (2008) Cathepsin activities and membrane integrity of zebrafish (Danio rerio) oocytes after freezing to -196 degrees C using controlled slow cooling. Cryobiology. 56(2): 138-43.

Zhang T, Wang Q, Yang H (2009) Involvement of Ca2+ Signaling Pathway During Oocyte Maturation of the Northern Quahog Mercenaria mercenaria. J Shellfish Res 28:527532. 


\section{Figures legend}

Figure 1 - Individual D-larval yield (mean \pm SD) obtained from 25 females of Ruditapes decussatus. The females were divided into three groups: Good quality (black bars), intermediate quality (white bars) and poor quality (grey bars) oocytes. Results are expressed as the percentage of oocytes that reached D-larval stage $48 \mathrm{~h}$ after fertilization

Figure 2 - Hierarchical clustering. Hierarchical clustering obtained using Pearson's correlation considering the set of 526 differentially expressed probes between the 10 females with the lowest D-larval yield and the 8 females of Ruditapes decussatus with the highest Dlarval yield analyzed. Heat map of oocyte quality specific genes. ( $\mathrm{P}-$ Poor quality oocytes / G - Good quality oocytes)

Figure 3 - Quantitative correlations. Negative correlations between gene expression values of a) Caspase 8 and b) Transcription factor E2F5 with the D-larval yield of Ruditapes decussatus 


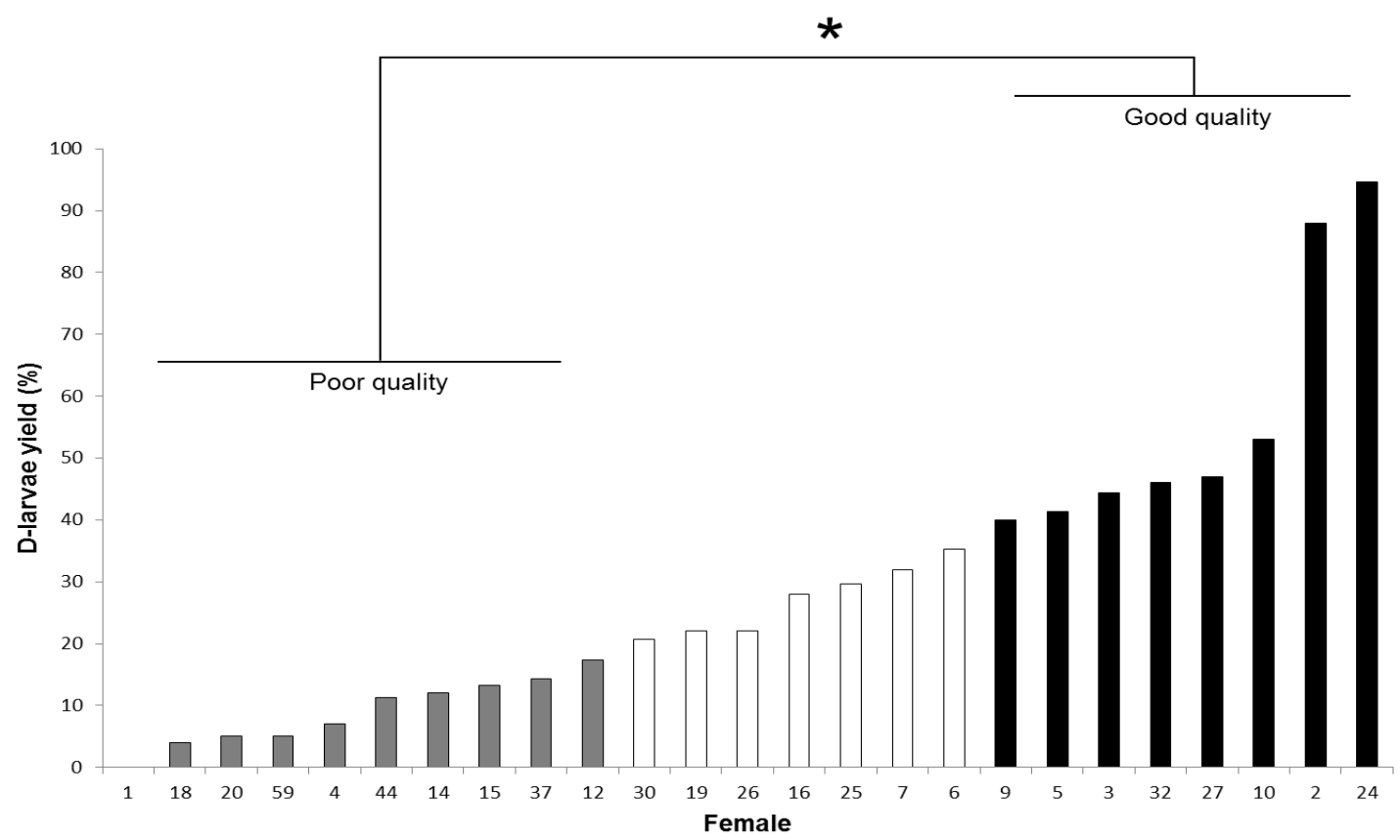

Figure 1 


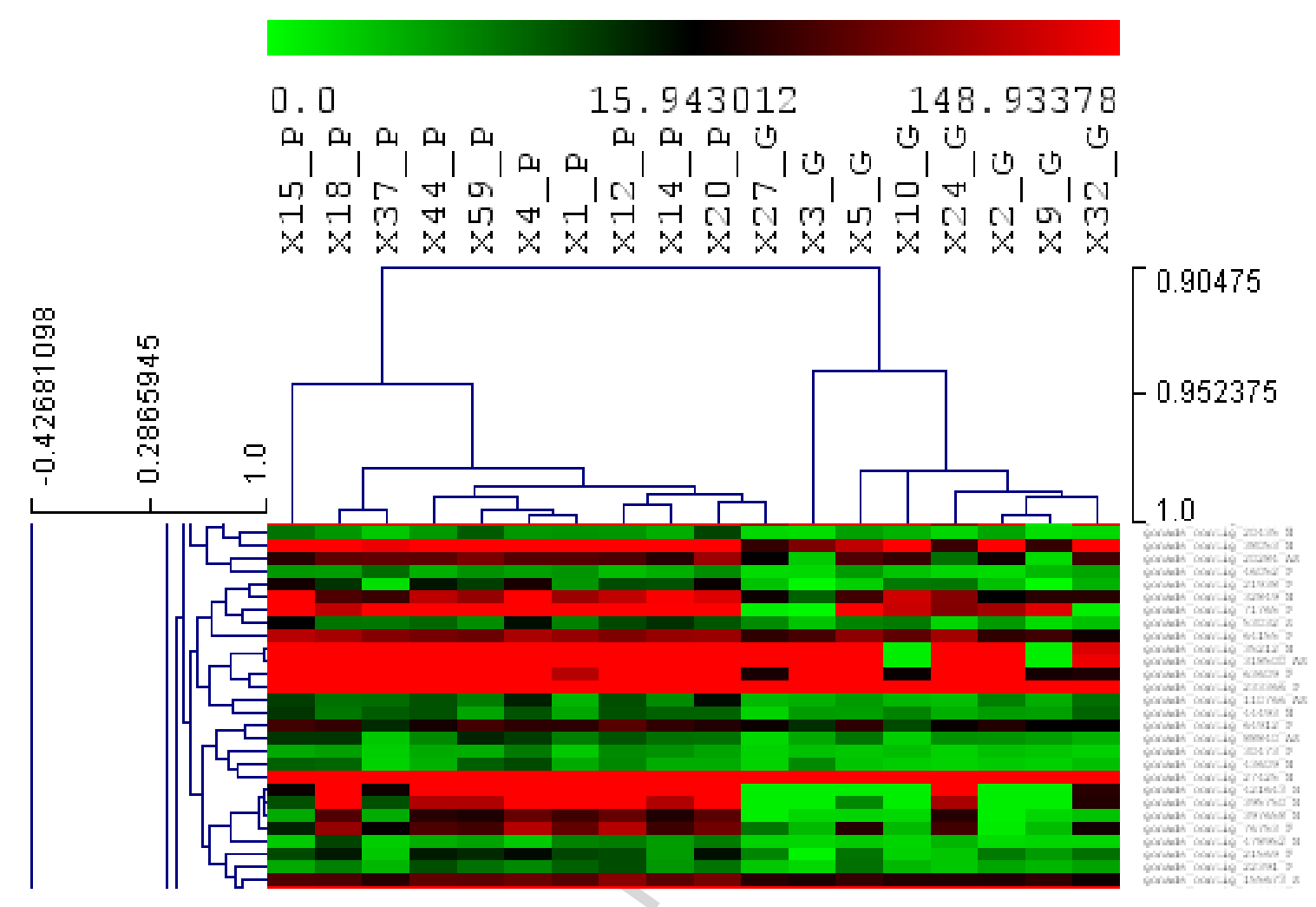

Figure 2 
a)

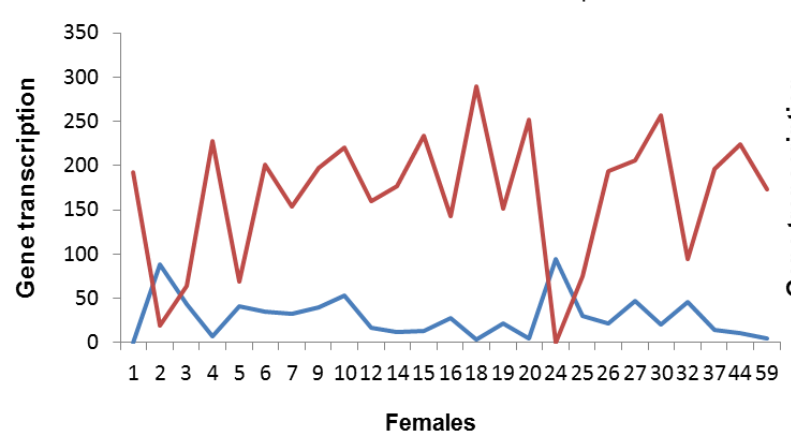

Figure 3 b) -D-arval rate - Transcription factor E2F5

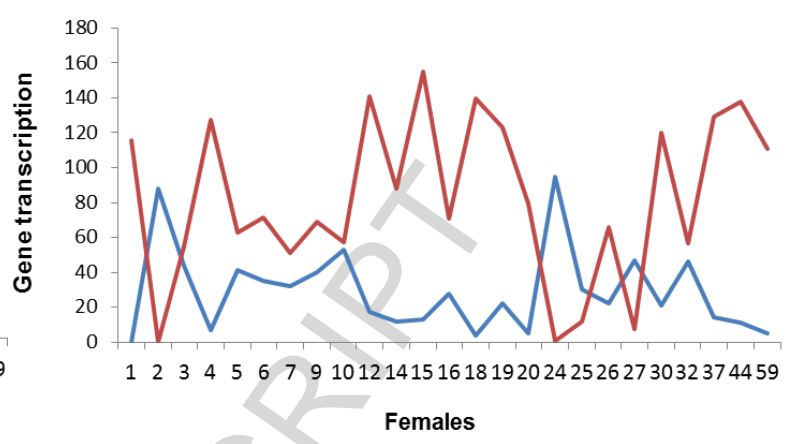

